Revue

Revue de l'histoire des religions

del'histoire

des religions

$1 \mid 2014$

Varia

\title{
Angélique de Saint-Jean Arnauld d'Andilly, Description de l'époux. Explications sur le Cantique des cantiques
}

Textes édités, introduits et annotés par Simon Icard en collaboration avec Bernard Koch, Grenoble, Jérôme Millon (« Atopia »), 2011

\section{François Trémolières}

\section{(2) OpenEdition}

\section{Journals}

Édition électronique

URL : http://journals.openedition.org/rhr/8229

DOI : $10.4000 /$ rhr.8229

ISSN : 2105-2573

Éditeur

Armand Colin

\section{Édition imprimée}

Date de publication : 1 mars 2014

Pagination : 155

ISBN : 978-2200929107

ISSN : 0035-1423

Référence électronique

François Trémolières, « Angélique de Saint-Jean Arnauld d'Andilly, Description de l'époux. Explications sur le Cantique des cantiques ", Revue de I'histoire des religions [En ligne], 1 | 2014, mis en ligne le 13 mai 2014, consulté le 22 septembre 2020. URL : http://journals.openedition.org/rhr/8229 ; DOI : https:// doi.org/10.4000/rhr.8229

Ce document a été généré automatiquement le 22 septembre 2020.

Tous droits réservés 


\section{Angélique de Saint-Jean Arnauld d'Andilly, Description de l'époux. Explications sur le Cantique des cantiques}

Textes édités, introduits et annotés par Simon Icard en collaboration avec Bernard Koch, Grenoble, Jérôme Millon (« Atopia »), 2011

\section{François Trémolières}

\section{RÉFÉRENCE}

Angélique de Saint-Jean Arnauld d'Andilly, Description de l'époux. Explications sur le Cantique des cantiques, textes édités, introduits et annotés par Simon Icard en collaboration avec Bernard Koch, Grenoble, Jérôme Millon (« Atopia »), 2011, 125 p., $19 \mathrm{~cm}, 17 €$, ISBN 978-2-84137-272-0.

1 Simon Icard avait signalé dans sa thèse publiée en 2010 : Port-Royal et saint Bernard de Clairvaux [voir RHR 2012-3, p. 452-455], tout l'intérêt de cette Description, manuscrit découvert par le P. Koch aux archives de la Congrégation de la Mission. Il en livre ici la première édition et l'accompagne des extraits concernant l'épithalame biblique dans les Discours et Conférences de l'abbesse, publiés au xviII siècle, qu'il fait suivre d'une lettre remarquable de son cousin Le Maistre de Sacy (le traducteur de la Bible), déjà connue, datée 1660 .

Fille de Robert Arnauld d'Andilly, Angélique, en religion Angélique de Saint-Jean (1624-1684), abbesse de Port-Royal de 1678 à sa mort, qui se distinguait par sa grande culture biblique et patristique, a beaucoup écrit et enseigné. La Description qui lui est attribuée se donne comme «l'explication suivie d'une péricope », Ct 5 10-16, dans la tradition monastique de la lectio divina mais en privilégiant nettement le sens moral, et avec une forte insistance sur la grâce. L'éditeur souligne avec raison qu'elle manifeste 
«une exigence toute classique », de clarté et de naturel: au lieu que le caractère « obscur » du poème embarrasse Sacy au point d'en différer sans cesse la traduction, il devient pour la sœur une invitation à l'interprétation.

3 Plus didactiques, voire prescriptives (l'adresse aux religieuses y est fréquente), les Explications sont tirées de commentaires à la règle de saint Benoît ou aux constitutions de Port-Royal. Un seul extrait renvoie à la même séquence - verset 16 : Tel est donc mon Bien-aimé... - qui contraste par sa froideur avec la Description, où l'on pouvait lire : « il n'y a que nos désirs qui peuvent le suivre de loin et que les larmes qu'ils nous font verser qui soient peut-être dignes d'obtenir qu'il se montre comme l'éclair, ou plutôt comme le soleil dans la nuée, pour nous éclairer et nous échauffer de sa présence, mais non pour nous découvrir toutes ses lumières dont notre vue est incapable. »

\section{AUTEURS}

FRANÇOIS TRÉMOLIÈRES

Université de Paris Ouest - Nanterre La Défense. 